\title{
Multicenter assessment of the reproducibility of volumetric radiofrequency-based intravascular ultrasound measurements in coronary lesions that were consecutively stented
}

\author{
Jennifer Huisman $\cdot$ Rasmus Egede $\cdot$ Adam Rdzanek • \\ Dirk Böse - Raimund Erbel · Janusz Kochman • Lisette Okkels Jensen • \\ Job van der Palen • Marc Hartmann • Gary S. Mintz • \\ Clemens von Birgelen
}

Received: 28 September 2011 / Accepted: 2 January 2012/Published online: 14 January 2012

(C) The Author(s) 2012. This article is published with open access at Springerlink.com

\begin{abstract}
To assess in a multicenter design the between-center reproducibility of volumetric virtual histology intravascular ultrasound (VH-IVUS) measurements with a semi-automated, computer-assisted contour detection system in coronary lesions that were consecutively stented. To evaluate the reproducibility of volumetric VH-IVUS measurements, experienced analysts of 4 European IVUS centers performed independent analyses (in total 8,052 cross-sectional analyses) to obtain volumetric data of 40 coronary segments (length $20.0 \pm 0.3 \mathrm{~mm}$ ) from target lesions prior to percutaneous intervention that were performed in the setting of stable $(65 \%)$ or unstable angina pectoris $(35 \%)$. Geometric and compositional
\end{abstract}

J. Huisman · M. Hartmann · C. von Birgelen $(\bowtie)$

Department of Cardiology, Thoraxcentrum Twente,

Haaksbergerstraat 55, 7513 ER Enschede,

The Netherlands

e-mail: c.vonbirgelen@mst.nl

R. Egede · L. O. Jensen

Department of Cardiology, Odense University Hospital,

Odense, Denmark

\section{A. Rdzanek · J. Kochman}

Department of Cardiology, Central University Hospital,

Warsaw, Poland

\section{Böse · R. Erbel}

Department of Cardiology, Westdeutsches Herzzentrum Essen, Universitätsklinikum Essen-Duisburg, Essen, Germany
VH-IVUS measurements were highly correlated for the different comparisons. Overall intraclass correlation for vessel, lumen, plaque volume and plaque burden was $0.99,0.92,0.96$, and 0.83 , respectively; for fibrous, fibro-lipidic, necrotic core and calcified volumes overall intraclass correlation was $0.96,0.94$, 0.98 , and 0.99 , respectively. Nevertheless, significant differences for both geometrical and compositional measurements were seen. Of the plaque components, fibrous tissue and necrotic core showed on average the highest measurement reproducibility. A central analysis for VH-IVUS multicenter studies of lesions prior to PCI should be pursued. Moreover, it may be problematical to pool VH-IVUS data of individual trials analyzed by independent centers.

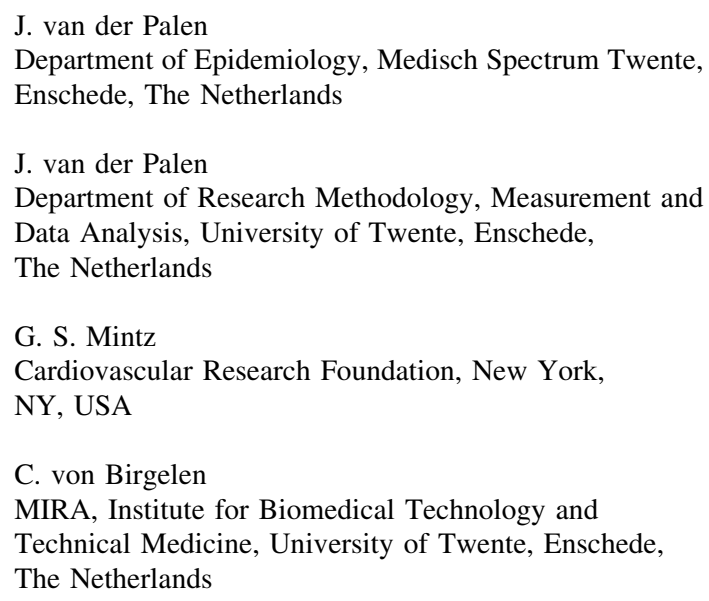


Keywords Coronary artery disease $\cdot$ Intravascular ultrasound · Radiofrequency · Virtual Histology · Measurement reproducibility · Percutaneous coronary interventions

$\begin{array}{ll}\text { Abbreviations } \\ \text { IVUS } & \text { Intravascular ultrasound } \\ \text { VH } & \text { Virtual histology } \\ \text { PCI } & \text { Percutaneous coronary intervention }\end{array}$

\section{Introduction}

Virtual Histology intravascular ultrasound (VHIVUS) allows measurements of both atherosclerotic plaque and vessel size and plaque composition in vivo [1-10]. Plaque composition of target lesions prior to percutaneous coronary intervention (PCI) may impact clinical outcome following PCI [11-19]. A relatively large necrotic core volume in target lesions as assessed with VH-IVUS is an independent predictor of creatine kinase and troponin elevation after PCI [11, 15]. Microembolization of such plaque components may lead to myocardial injury during stent implantation $[11,14,16,18,20]$. Certain plaque components or phenotypes as assessed with VH-IVUS are related to no-reflow phenomenon post-PCI which may be triggered by such microembolization and adversely affects prognosis [14, 18]. Therefore, volumetric VH-IVUS assessment of target lesions prior to PCI may have the potential to identify lesions at particularly high risk for such complications and may help to tailor such procedures. However, an important prerequisite for clinical VH-IVUS studies assessing such relations in advanced coronary lesions prior to PCI is an adequate measurement reproducibility [2].

We recently reported significant but small differences for VH-IVUS measurements of mild-to-moderately diseased coronary segments between different European IVUS centers [21]. But so far, no data is available on the between-center reproducibility of VH-IVUS measurements of advanced lesions prior to PCI. Therefore, in the present study we assessed the between-center reproducibility of volumetric VH-IVUS measurements of target lesions, that were consecutively stented, by comparing data from repeated analyses as performed by independent analysts at 4 independent IVUS centers in Europe.

\section{Methods}

Study population

In order to assess the between-center reproducibility of segmental volumetric VH-IVUS data analysis of diseased atherosclerotic human coronary arteries, we performed IVUS analyses in $20 \mathrm{~mm}$-long segments of coronary lesions prior to PCI in patients with unstable angina pectoris or stable angina. Coronary segments had to meet the following inclusion criteria: no severe plaque calcification, no major vessel tortuosity, and/or major side-branches. In this multicenter study design, 4 experienced analysts independently performed $\mathrm{VH}-$ IVUS analyses of all segments included in the study. Each IVUS center was invited to submit IVUS pullbacks of 10 coronary segments obtained from patients in sinus rhythm in whom a clinically driven cardiac catheterization required IVUS assessment prior to PCI. Participating centers were Odense University Hospital, Odense, Denmark; Essen University Hospital, Essen, Germany; Central University Hospital, Warsaw, Poland; and Thoraxcentrum Twente, Enschede, The Netherlands.

\section{IVUS data acquisition}

Acquisition of IVUS data was performed in an ECG-gated way with commercially available phasedarray IVUS catheters (Eagle Eye Gold 2.9F $20 \mathrm{MHz}$, Volcano Corporation, Rancho Cordova, CA, USA) with a dedicated console [22]. The IVUS transducer was advanced $\geq 10 \mathrm{~mm}$ distal to the most distal side-branch. Angiographic cine runs were performed to define the position of the IVUS transducer. After intracoronary injection of $200 \mu \mathrm{g}$ nitroglycerin, a continuous pullback of the IVUS catheter was performed using a motorized pullback device at $0.5 \mathrm{~mm} / \mathrm{s}$ (TrackBack-II, Volcano Corporation). IVUS image data were stored on digital video disk (DVD) for offline analysis.

VH-IVUS data analysis

Description of the technique and the validation of VH-IVUS have previously been published $[1,3,4,6]$. In brief, tissue maps are reconstructed from spectral IVUS radiofrequency data and classify the plaque in four major components: calcium, fibro-lipidic, fibrous, and necrotic core. Tissue components were displayed 
according to a color code (white, light-green, green, and red, respectively).

Offline VH-IVUS analysis of all cases was performed by one experienced IVUS analyst per center (Fig. 1). The IVUS sequences were provided with a predefined region of interest (20 mm length) that contained a (part of a) target lesion for PCI. Segments were located between two adjacent side-branches and contained no major calcification that could have limited reliable detection of the external vascular boundary.

By use of the VH-images and software, IVUS measurements of geometry and plaque composition were made. The lumen and vessel borders were traced using a semi-automated, computer-assisted contour detection program (Volcano pcVH software program version 2.2; Volcano); to exclude potential between version differences of the analysis software, all four centers used the

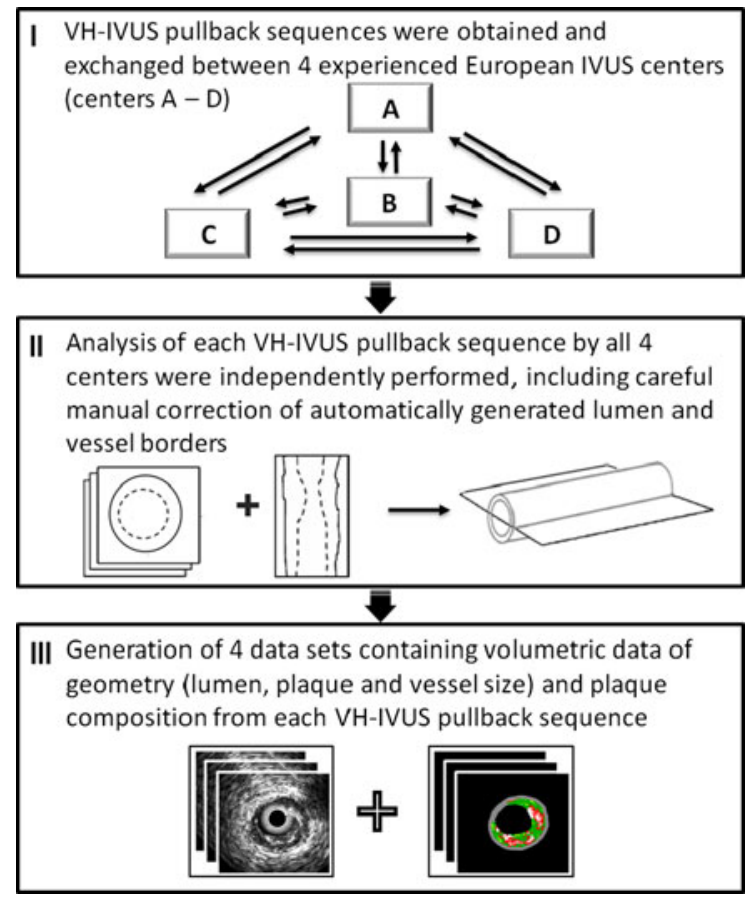

Fig. 1 Image acquisition and data analysis. Motorized pullbacks at $0.5 \mathrm{~mm} / \mathrm{s}$ (including image frame acquisition at the time of the R-wave peak) were performed by each IVUS center $(A-D)$. These pullback sequences (obtained from 10 patients) were exchanged in order to obtain a 'pullback pool' of 40 pullbacks, which each analyst independently analyzed (I). Automated contour detection and, if required, manual correction of the lumen and vessel border were performed on all frames using the VH-images and software (II). Volumetric VH-IVUS data of vessel and plaque geometry and plaque composition were automatically generated for the analyzed segment based on the application of Trapezium method (III) latest version of the analysis software. The leading edge of the blood-intima acoustic interface and the leading edge of the media-adventitia interface were automatically detected to define the lumen and vessel borders, respectively, and manually corrected as required. Plaque \& media was used as a measure of atherosclerotic plaque and was calculated as the difference between vessel and lumen cross-sectional area. For each coronary segment, volumetric data of the vessel, lumen, plaque and plaque burden, as well as fibrous, fibro-lipidic, necrotic core, and calcified tissue were obtained from the application of the trapezium method to the cross-sectional area measurements [21, 23]. The $\mathrm{pcVH}$ software program uses this method that considers the exact spacing between image frames to calculate volumes from the cross-sectional area data in the most accurate way. In addition, the relative amount of the four plaque components was calculated. To account for any differences in length, all volumetric data were normalized for $10 \mathrm{~mm}$-long segments [21, 23].

In order to assess the between-center reproducibility of volumetric VH-IVUS analyses, comparisons were performed on a two-observer basis (i.e., center A vs. B, C and D respectively; center B vs. C and D respectively; and center $\mathrm{C}$ vs. D).

\section{Statistical analysis}

Statistical analysis was performed with SPSS 15.0 (SPSS Inc., Chicago, IL, USA). Dichotomous variables are presented as frequencies, while quantitative data are presented as mean $\pm 1 \mathrm{SD}$ (or $\pm 1 \mathrm{SEM}$ ). Quantitative data were compared by use of a paired $t$ test after Normality of the data was confirmed. A two-sided $P$-value $<0.05$ was considered as significant. According to Bland and Altman, the agreement between two measurements was assessed by determining the mean $\pm 2 \mathrm{SD}$ of the between measurement differences [24]. Intra-class correlations were calculated for comparisons at an individual level. An intra-class correlation $>0.90$ was considered good.

\section{Results}

Study population

A total of 40 coronary segments (6 right; 27 left anterior descending; and 7 left circumflex coronary 
arteries) were analyzed from 40 patients (age $64 \pm 10$ years, $75 \%$ were male) who were in sinus rhythm during the IVUS pullback. IVUS examination was performed in both patients with stable syndromes $(65 \%)$ and unstable syndromes (35\%). Eighty-eight percent of the patients was on statin therapy prior to the cardiac catheterization, and $35 \%$ was diabetics. There was no complication related to IVUS imaging.

VH-IVUS analysis and data

Independent analysis of each of the 40 coronary segments was performed by each of the four analysts and volumetric data was obtained to evaluate the reproducibility of volumetric VH-IVUS measurements $(50 \pm 14$ frames/segment). This approach required the analysis of a total of 8,052 cross-sectional frames (2,013 frames per analyst). Manual correction of the automatic border detection was required in almost all frames for a total analysis time of $60 \pm$ $6 \mathrm{~min} / \mathrm{segment}$. The length of the analyzed segments was $20.0 \pm 0.3 \mathrm{~mm}$ (range: $19.1-20.6 \mathrm{~mm}$ ). On average, the atherosclerotic segments contained predominantly fibrous $(57.4 \%)$, fibro-lipidic $(13.1 \%)$, and necrotic core (19.1\%) tissue. Geometric and compositional IVUS data obtained by the analysts of the 4 different centers (A-D) are presented in Table 1.
VH-IVUS measurement variability of plaque and vessel geometry

VH-IVUS measurements of vessel geometry were highly correlated for the different comparisons. Overall intra-class correlation and range of the individual between-center comparisons (within brackets) was for vessel, lumen, plaque volume and plaque burden 0.99 (0.98-1.00), 0.92 (0.84-0.97), 0.96 (0.93-0.98), and 0.83 (0.75-0.90), respectively. Although there were significant differences for vessel, lumen, and plaque volumes, these differences were only moderate in size (Tables 1, 2; Fig. 2). Plaque burden also showed significant differences for the comparisons between two centers. However, the differences were only moderate in size, ranging from 0.8 to $4.6 \%$. Statistical analysis using Anova with Holm-Bonferroni correction did not show significant differences, except for plaque burden measurements of center $\mathrm{C}$ versus $\mathrm{D}$ (adjusted $P$-value 0.048), no significant differences were seen $(P>0.1$, Table 1$)$. The limits of agreement (i.e., $2 \mathrm{SD}$ of mean difference) were relatively small and similar for the different comparisons; measurement reproducibility of vessel volume was particularly high (Fig. 3a, b). Measurement reproducibility was not influenced by the size of the measured volumes.

Table 1 VH-IVUS data from four different centers (A-D)

\begin{tabular}{|c|c|c|c|c|c|}
\hline & A & B & $\mathrm{C}$ & $\mathrm{D}$ & ANOVA \\
\hline \multicolumn{6}{|l|}{ Vessel geometrics } \\
\hline Vessel volume $\left(\mathrm{mm}^{3}\right)$ & $162.8 \pm 36.3$ & $156.9 \pm 37.7$ & $163.1 \pm 36.7$ & $159.4 \pm 36.4$ & 0.9 \\
\hline Lumen volume $\left(\mathrm{mm}^{3}\right)$ & $73.8 \pm 16.5$ & $74.3 \pm 17.3$ & $78.9 \pm 18.6$ & $69.8 \pm 17.1$ & 0.2 \\
\hline Plaque volume $\left(\mathrm{mm}^{3}\right)$ & $89.0 \pm 25.7$ & $82.6 \pm 26.9$ & $84.3 \pm 25.0$ & $89.5 \pm 26.1$ & 0.7 \\
\hline Plaque burden $(\%)$ & $54.2 \pm 6.8$ & $52.0 \pm 7.7$ & $51.3 \pm 7.6$ & $55.8 \pm 7.5$ & $0.051 *$ \\
\hline \multicolumn{6}{|l|}{ Plaque composition } \\
\hline Fibrous volume $\left(\mathrm{mm}^{3}\right)$ & $31.0 \pm 16.1$ & $27.9 \pm 16.1$ & $28.1 \pm 14.9$ & $31.7 \pm 15.8$ & 0.8 \\
\hline Fibrous volume (\%) & $58.0 \pm 9.9$ & $56.8 \pm 11.0$ & $57.3 \pm 10.6$ & $57.6 \pm 10.1$ & 1.0 \\
\hline Fibro-lipidic volume $\left(\mathrm{mm}^{3}\right)$ & $7.0 \pm 4.9$ & $6.3 \pm 4.9$ & $5.8 \pm 4.2$ & $7.3 \pm 5.0$ & 0.7 \\
\hline Fibro-lipidic volume (\%) & $13.4 \pm 9.1$ & $13.1 \pm 9.0$ & $12.3 \pm 8.2$ & $13.7 \pm 8.7$ & 1.0 \\
\hline Necrotic core volume $\left(\mathrm{mm}^{3}\right)$ & $10.0 \pm 6.0$ & $9.2 \pm 6.0$ & $9.6 \pm 6.2$ & $10.3 \pm 6.6$ & 1.0 \\
\hline Necrotic core volume $(\%)$ & $18.7 \pm 9.0$ & $19.2 \pm 9.2$ & $19.5 \pm 9.0$ & $18.7 \pm 9.0$ & 1.0 \\
\hline Calcium volume $\left(\mathrm{mm}^{3}\right)$ & $4.9 \pm 3.7$ & $4.9 \pm 3.7$ & $5.0 \pm 3.7$ & $5.1 \pm 3.9$ & 1.0 \\
\hline Calcium volume (\%) & $9.9 \pm 7.7$ & $10.9 \pm 8.7$ & $10.8 \pm 8.3$ & $9.9 \pm 7.9$ & 1.0 \\
\hline
\end{tabular}

Values are normalized to $10 \mathrm{~mm}$ segment length and presented as mean \pm standard deviation and ANOVA

* Significant difference could be explained by the comparison between center C and D (adjusted $P=0.048$ (Holm-Bonferroni correction), the other comparisons were not significant 
Table 2 Measurement differences of VH-IVUS data from four different centers (A-D)

\begin{tabular}{|c|c|c|c|c|c|c|}
\hline & \multicolumn{3}{|l|}{ A versus* } & \multicolumn{2}{|l|}{$\mathrm{B}$ versus* } & \multirow{2}{*}{$\begin{array}{l}\text { C versus* } \\
\text { D }\end{array}$} \\
\hline & $\mathrm{B}$ & $\mathrm{C}$ & $\mathrm{D}$ & $\mathrm{C}$ & $\mathrm{D}$ & \\
\hline \multicolumn{7}{|l|}{ Vessel geometry } \\
\hline$\Delta$ Vessel volume $\left(\mathrm{mm}^{3}\right)$ & $\begin{array}{l}5.9 \pm 0.8 \\
P<0.01\end{array}$ & $\begin{array}{l}-0.3 \pm 0.5 \\
P=0.5\end{array}$ & $\begin{array}{l}3.4 \pm 0.5 \\
P<0.01\end{array}$ & $\begin{array}{l}-6.2 \pm 0.8 \\
P<0.01\end{array}$ & $\begin{array}{l}-2.5 \pm 0.8 \\
P<0.01\end{array}$ & $\begin{array}{l}3.8 \pm 0.6 \\
P<0.01\end{array}$ \\
\hline$\Delta$ Lumen volume $\left(\mathrm{mm}^{3}\right)$ & $\begin{array}{l}-0.6 \pm 0.7 \\
P=0.4\end{array}$ & $\begin{array}{l}-5.1 \pm 0.9 \\
P<0.01\end{array}$ & $\begin{array}{l}3.9 \pm 0.7 \\
P<0.01\end{array}$ & $\begin{array}{l}-4.5 \pm 0.9 \\
P<0.01\end{array}$ & $\begin{array}{l}4.5 \pm 0.8 \\
P<0.01\end{array}$ & $\begin{array}{l}9.0 \pm 0.9 \\
P<0.01\end{array}$ \\
\hline$\Delta$ Plaquee volume $\left(\mathrm{mm}^{3}\right)$ & $\begin{array}{l}6.5 \pm 0.9 \\
P<0.01\end{array}$ & $\begin{array}{l}4.8 \pm 0.9 \\
P<0.01\end{array}$ & $\begin{array}{l}-0.5 \pm 0.8 \\
P=0.5\end{array}$ & $\begin{array}{l}-1.7 \pm 1.2 \\
P=0.2\end{array}$ & $\begin{array}{l}-7.0 \pm 1.2 \\
P<0.01\end{array}$ & $\begin{array}{l}-5.3 \pm 0.9 \\
P<0.01\end{array}$ \\
\hline$\Delta$ Plaque burden $(\%)$ & $\begin{array}{l}2.2 \pm 0.5 \\
P<0.01\end{array}$ & $\begin{array}{l}3.0 \pm 0.5 \\
P<0.01\end{array}$ & $\begin{array}{l}-1.6 \pm 0.5 \\
P<0.01\end{array}$ & $\begin{array}{l}0.8 \pm 0.6 \\
P=0.2\end{array}$ & $\begin{array}{l}-3.8 \pm 0.6 \\
P<0.01\end{array}$ & $\begin{array}{l}-4.6 \pm 0.5 \\
P<0.01\end{array}$ \\
\hline \multicolumn{7}{|l|}{ Plaque composition } \\
\hline$\Delta$ Fibrous volume $\left(\mathrm{mm}^{3}\right)$ & $\begin{array}{l}3.0 \pm 0.6 \\
P<0.01\end{array}$ & $\begin{array}{l}2.9 \pm 0.5 \\
P<0.01\end{array}$ & $\begin{array}{l}-0.7 \pm 0.4 \\
P=0.1\end{array}$ & $\begin{array}{l}-0.1 \pm 0.7 \\
P=0.9\end{array}$ & $\begin{array}{l}-3.7 \pm 0.7 \\
P<0.01\end{array}$ & $\begin{array}{l}-3.6 \pm 0.5 \\
P<0.01\end{array}$ \\
\hline$\Delta$ Fibrous volume $(\%)$ & $\begin{array}{l}1.2 \pm 0.3 \\
P<0.01\end{array}$ & $\begin{array}{l}0.7 \pm 0.3 \\
P<0.01\end{array}$ & $\begin{array}{l}0.4 \pm 0.2 \\
P=0.02\end{array}$ & $\begin{array}{l}-0.5 \pm 0.2 \\
P=0.04\end{array}$ & $\begin{array}{l}-0.8 \pm 0.2 \\
P<0.01\end{array}$ & $\begin{array}{l}-0.3 \pm 0.2 \\
P=0.2\end{array}$ \\
\hline$\Delta$ Fibro-lipidic volume $\left(\mathrm{mm}^{3}\right)$ & $\begin{array}{l}0.8 \pm 0.2 \\
P<0.01\end{array}$ & $\begin{array}{l}1.2 \pm 0.3 \\
P<0.01\end{array}$ & $\begin{array}{l}-0.3 \pm 0.2 \\
P=0.1\end{array}$ & $\begin{array}{l}0.4 \pm 0.2 \\
P=0.1\end{array}$ & $\begin{array}{l}-1.0 \pm 0.3 \\
P<0.01\end{array}$ & $\begin{array}{l}-1.5 \pm 0.2 \\
P<0.01\end{array}$ \\
\hline$\Delta$ Fibro-lipidic volume $(\%)$ & $\begin{array}{l}0.3 \pm 0.3 \\
P=0.3\end{array}$ & $\begin{array}{l}1.0 \pm 0.2 \\
P<0.01\end{array}$ & $\begin{array}{l}-0.3 \pm 0.2 \\
P=0.1\end{array}$ & $\begin{array}{l}0.7 \pm 0.3 \\
P=0.02\end{array}$ & $\begin{array}{l}-0.7 \pm 0.3 \\
P=0.05\end{array}$ & $\begin{array}{l}-1.4 \pm 0.2 \\
P<0.01\end{array}$ \\
\hline$\Delta$ Necrotic core volume $\left(\mathrm{mm}^{3}\right)$ & $\begin{array}{l}0.7 \pm 0.2 \\
P<0.01\end{array}$ & $\begin{array}{l}0.4 \pm 0.2 \\
P=0.02\end{array}$ & $\begin{array}{l}-0.4 \pm 0.2 \\
P=0.08\end{array}$ & $\begin{array}{l}-0.3 \pm 0.2 \\
P=0.06\end{array}$ & $\begin{array}{l}-1.1 \pm 0.2 \\
P<0.01\end{array}$ & $\begin{array}{l}-0.8 \pm 0.2 \\
P<0.01\end{array}$ \\
\hline$\Delta$ Necrotic core volume $(\%)$ & $\begin{array}{l}-0.5 \pm 0.2 \\
P=0.05\end{array}$ & $\begin{array}{l}-0.8 \pm 0.2 \\
P<0.01\end{array}$ & $\begin{array}{l}-0.00 \pm 0.2 \\
P=1.0\end{array}$ & $\begin{array}{l}-0.3 \pm 0.2 \\
P=0.1\end{array}$ & $\begin{array}{l}0.5 \pm 0.2 \\
P=0.05\end{array}$ & $\begin{array}{l}0.8 \pm 0.2 \\
P<0.01\end{array}$ \\
\hline$\Delta$ Calcium volume $\left(\mathrm{mm}^{3}\right)$ & $\begin{array}{l}0.02 \pm 0.1 \\
P=0.7\end{array}$ & $\begin{array}{l}-0.1 \pm 0.1 \\
P=0.3\end{array}$ & $\begin{array}{l}-0.2 \pm 0.1 \\
P=0.03\end{array}$ & $\begin{array}{l}-0.1 \pm 0.1 \\
P=0.2\end{array}$ & $\begin{array}{l}-0.2 \pm 0.1 \\
P=0.03\end{array}$ & $\begin{array}{l}-0.1 \pm 0.1 \\
P=0.2\end{array}$ \\
\hline$\Delta$ Calcium volume $(\%)$ & $\begin{array}{l}-1.0 \pm 0.2 \\
P<0.01\end{array}$ & $\begin{array}{l}-1.0 \pm 0.2 \\
P<0.01\end{array}$ & $\begin{array}{l}-0.1 \pm 0.1 \\
P=0.6\end{array}$ & $\begin{array}{l}0.1 \pm 0.2 \\
P=0.7\end{array}$ & $\begin{array}{l}1.0 \pm 0.2 \\
P<0.01\end{array}$ & $\begin{array}{l}0.9 \pm 0.2 \\
P<0.01\end{array}$ \\
\hline
\end{tabular}

Values are normalized to $10 \mathrm{~mm}$ segment length and presented as mean \pm standard error of the mean. * Two-sided paired $t$ test

VH-IVUS measurement variability of plaque composition

VH-IVUS measurements of plaque composition were highly correlated for the different comparisons. Overall intra-class correlation and range of the individual between-center comparisons (within brackets) for (absolute) fibrous, fibro-lipidic, necrotic core and calcified volume was 0.96 (0.94-0.98), 0.94 (0.91-0.97), 0.98 (0.96-0.99), and 0.99 (0.98-0.99), respectively. There were significant differences for all plaque components (Tables 1,2). The limits of agreement (i.e., $2 \mathrm{SD}$ of mean difference) for compositional data were higher compared to geometrical data, but similar for the different comparisons (Fig. 4a, b). Fibrous tissue and necrotic core showed the highest measurement reproducibility.
Smaller fibrous and fibro-lipidic volumes tended to show somewhat higher between-center variability.

\section{Discussion}

In the present study, we evaluated the between-center reproducibility of VH-IVUS measurements of target lesions prior to PCI. VH-IVUS measurements of plaque and vessel dimensions and plaque composition were highly correlated for the different comparisons (overall ICC 0.83-0.99). However, we found significant between-center differences for vessel dimensions (relative differences of $\leq 4 \%, \leq 12 \%, \leq 9 \%$, and $\leq 9 \%$; vessel, lumen, and plaque volume and plaque burden, respectively) and plaque composition (relative 

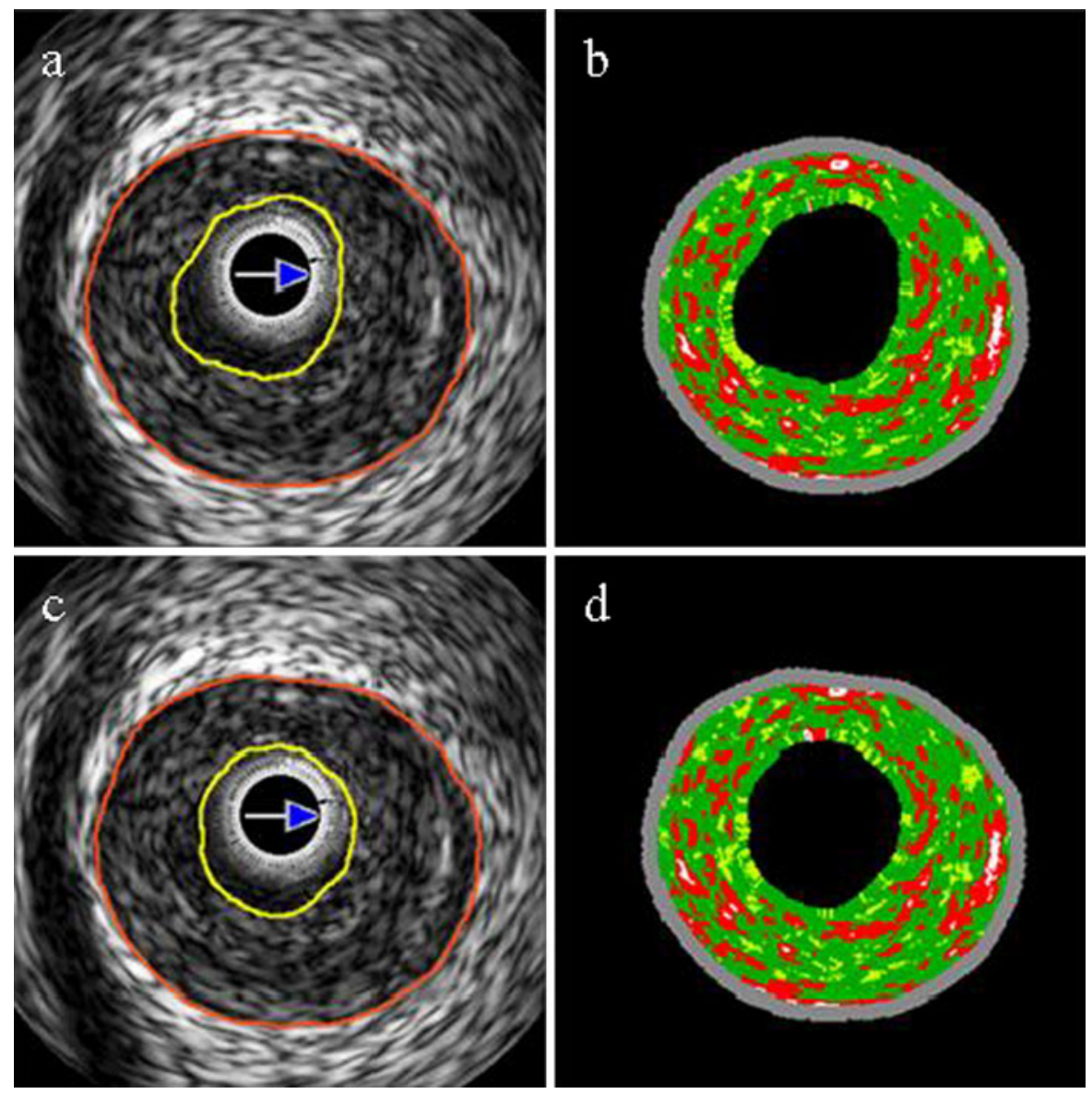

Fig. 2 Example of differences in contour detection in a single frame. The same coronary segment was analyzed by 2 different centers; please note that differences in contour detection

resulted in differences in plaque composition. Center $A$ (Greyscale (a) and VH-IVUS (b) analysis) versus Center B (c and $\mathbf{d}$, resp)

differences of $\leq 15 \%, \leq 25 \%, \leq 11 \%$, and $\leq 6 \%$; fibrous, fibro-lipidic, necrotic core, and calcified plaque components, respectively). The highest measurement reproducibility for plaque components was found for fibrous tissue and necrotic core.

\section{Rationale of VH-IVUS assessment of coronary} lesions prior to PCI

Percutaneous coronary interventions may cause microembolization of unstable plaque material, which can lead to no-reflow phenomenon, myocardial microinfarcts with cardiac marker release and impaired left ventricular function, and significantly impaired clinical outcome [11, 14, 16, 18, 20]. Several VH-IVUS studies demonstrated that differences in plaque composition of target lesions are related to such post-PCI events

[11-19]. Hong et al. showed that relative necrotic core volumes were significantly larger in patients with elevated troponin levels following PCI $(19.8 \pm 10.4 \%$ vs. $12.8 \pm 8.4 \%, P=0.015$ ) [15]. Böse et al. reported that cardiac marker release following PCI was much greater in plaques with a large necrotic core volume $\left(>10.81 \mathrm{~mm}^{3} ; P<0.001\right)$ with a trend for a lower increase of cardiac markers in patients treated with statins before PCI [11]. Certain plaque components or phenotypes as assessed with VH-IVUS are related to no-reflow phenomenon post-PCI which may be triggered by such microembolization and adversely effects prognosis $[14,18]$. Hong et al. reported that relative necrotic core volume serves as an independent predictor of no-reflow post-stenting in patients with acute coronary syndrome (odds ratio $=1.126 ; 95 \% \mathrm{CI}$ 1.045-1.214, $P=0.002$ ) [14]. 

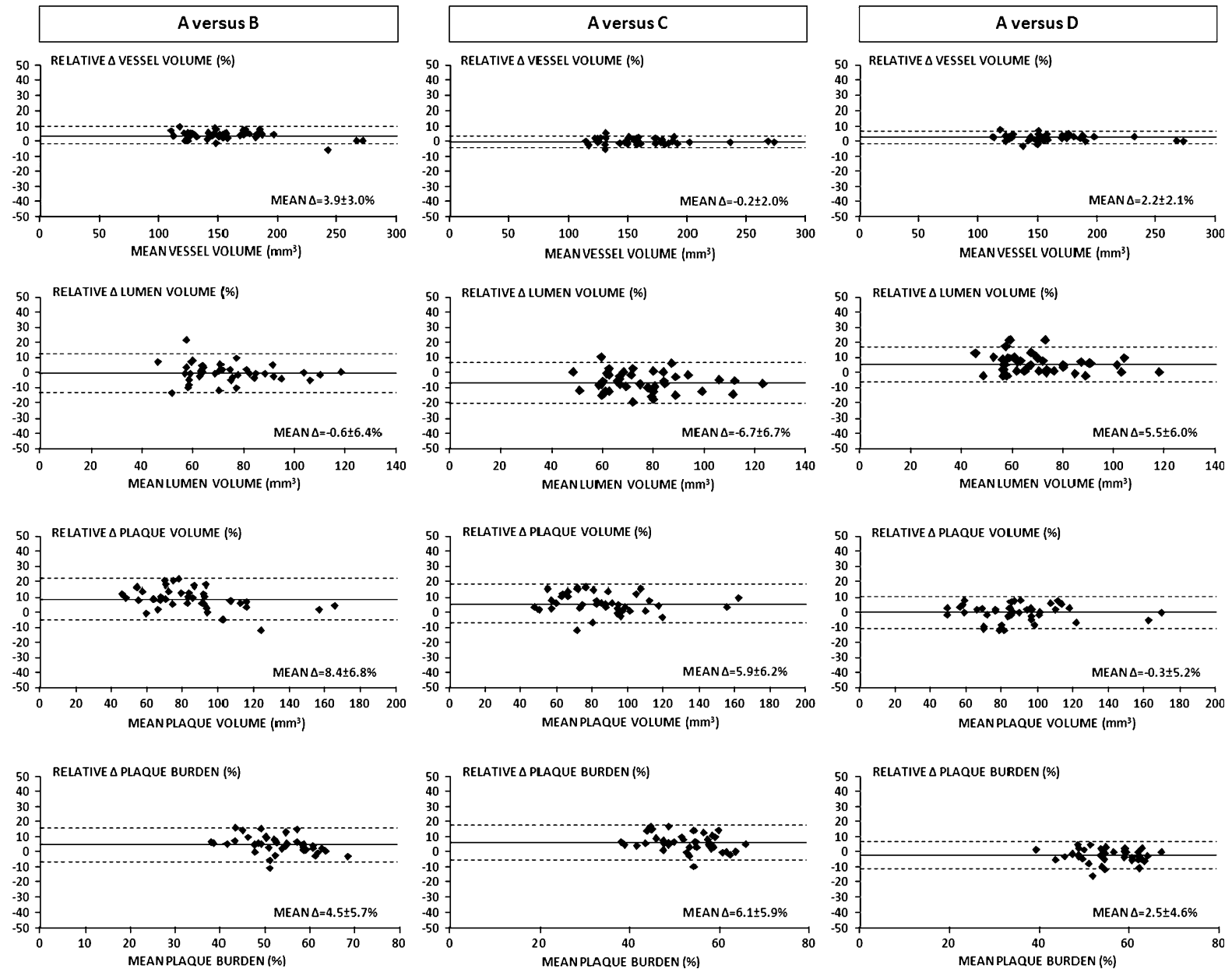

Fig. 3 a Agreement of repeated VH-IVUS measurements of geometric volumes. Agreement of repeated VH-IVUS measurements of geometry between center $A$ versus $B$ (left), center $A$ versus $C$ (mid) and center $A$ versus $D$ (right). $\Delta=$ difference.

Therefore, volumetric VH-IVUS assessment of target lesions prior to PCI may have the potential to identify lesions at particularly high risk for such complications and may help to tailor interventions (i.e., embolic protection device, direct stenting vs. pre-dilatation etc.) and may help to optimize systemic medical therapy (i.e., therapy with very high dose statins, or novel anti-atherosclerotic or platelet inhibiting drugs) [25, 26]. However, only large multicenter trials will be able to determine the clinical value of the assessment of plaque composition with VH-IVUS prior to PCI. An important prerequisite for clinical VH-IVUS studies assessing such relations in advanced coronary lesions, is an adequate measurement reproducibility of VH-IVUS especially b Agreement of repeated VH-IVUS measurements of geometric volumes. Agreement of repeated VH-IVUS measurements of geometry between center $B$ versus $C$ (left), center $B$ versus $D$ (mid) and center $C$ versus $D$ (right). $\Delta=$ difference

when pooled IVUS data is used in multicenter trials or registries [2].

Measurement reproducibility and studies with multicenter design

Several prior single-center studies demonstrated sufficient reproducibility of VH-IVUS measurements between observers, catheters, and repeated pullbacks $[2,8,9,21,23]$.

Rodriguez-Granillo et al. assessed the measurement variability of VH-IVUS cross-sectional data obtained form 16 mild coronary plaques in a singlecenter design. The relative intra-observer difference was $<11 \%$ for plaque cross-sectional area and 

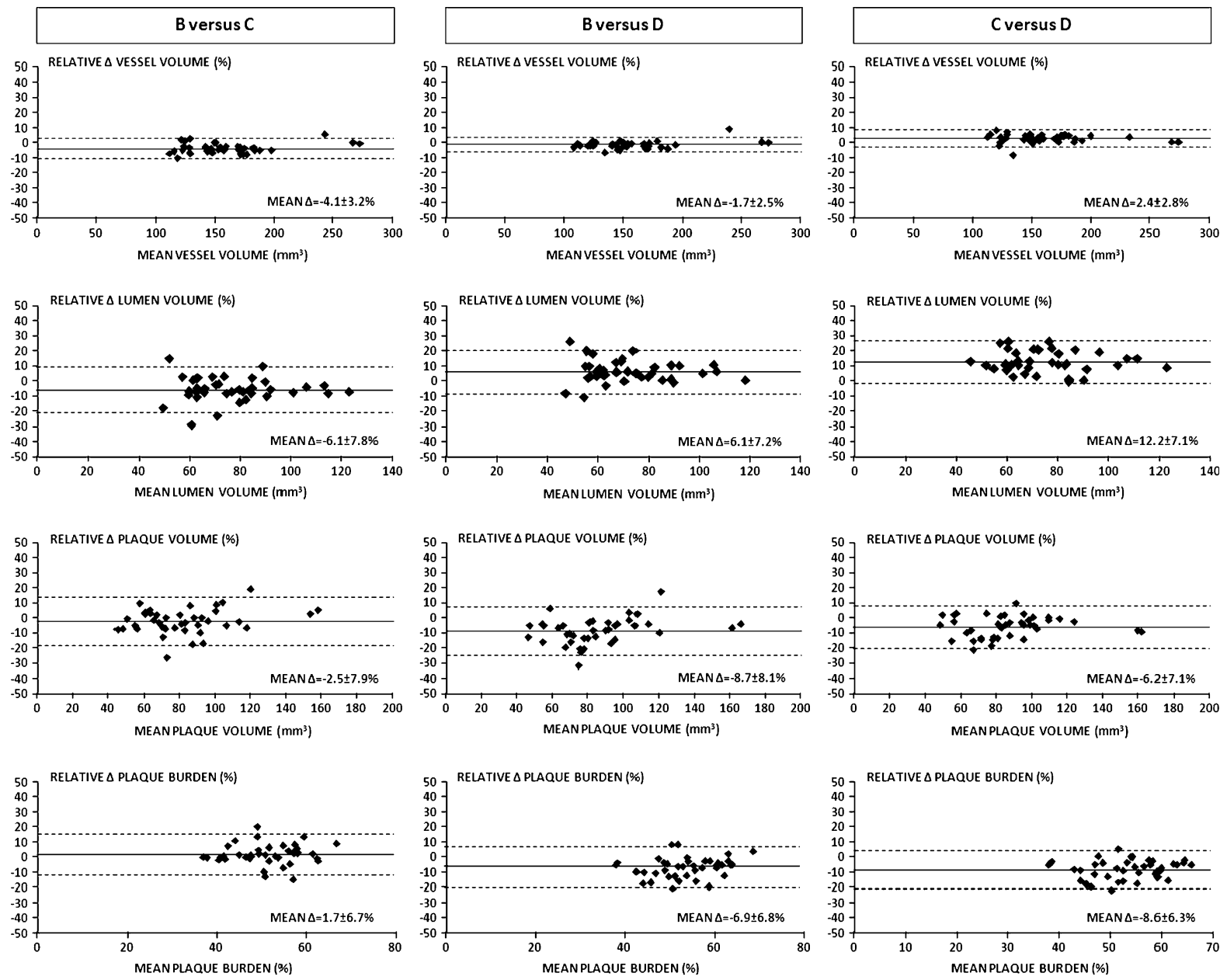

Fig. 3 continued

compositional measurements showed a variability up to $24 \%$ [9]. Prasad et al. assessed volumetric VHIVUS measurement variability of 16 significant coronary plaques (mean plaque burden of 55\%) prior to PCI and reported high agreement for geometrical and compositional measurements (Spearman's correlation $>0.8$ ) in a single-center design [8]. A relatively high intra- and interobserver reproducibility of volumetric geometric and compositional VH-IVUS data was previously described by Hartmann et al. in a series of 33 mild-to-moderate diseased coronary segments [2].

However, the aforementioned studies assessed VHIVUS measurement variability of analysts from a single center or core lab with the same training background. In a previous multicenter study by this group of investigators, we demonstrated in coronary segments with mild-to-moderate coronary atherosclerosis a higher measurement variability and small but significant measurement differences between analysts from 4 different IVUS centers with different training programs [21]. In the current study, in much more advanced atherosclerotic lesions, VH-IVUS measurements of vessel geometry and plaque composition showed, despite good correlation between the four IVUS centers, significant differences for both vessel geometry and plaque composition. These differences could affect the results of multicenter trials with VH-IVUS.

Implications for multicenter VH-IVUS studies of coronary lesions prior to PCI

VH-IVUS measurement differences may have resulted from systematic over or underestimation of 

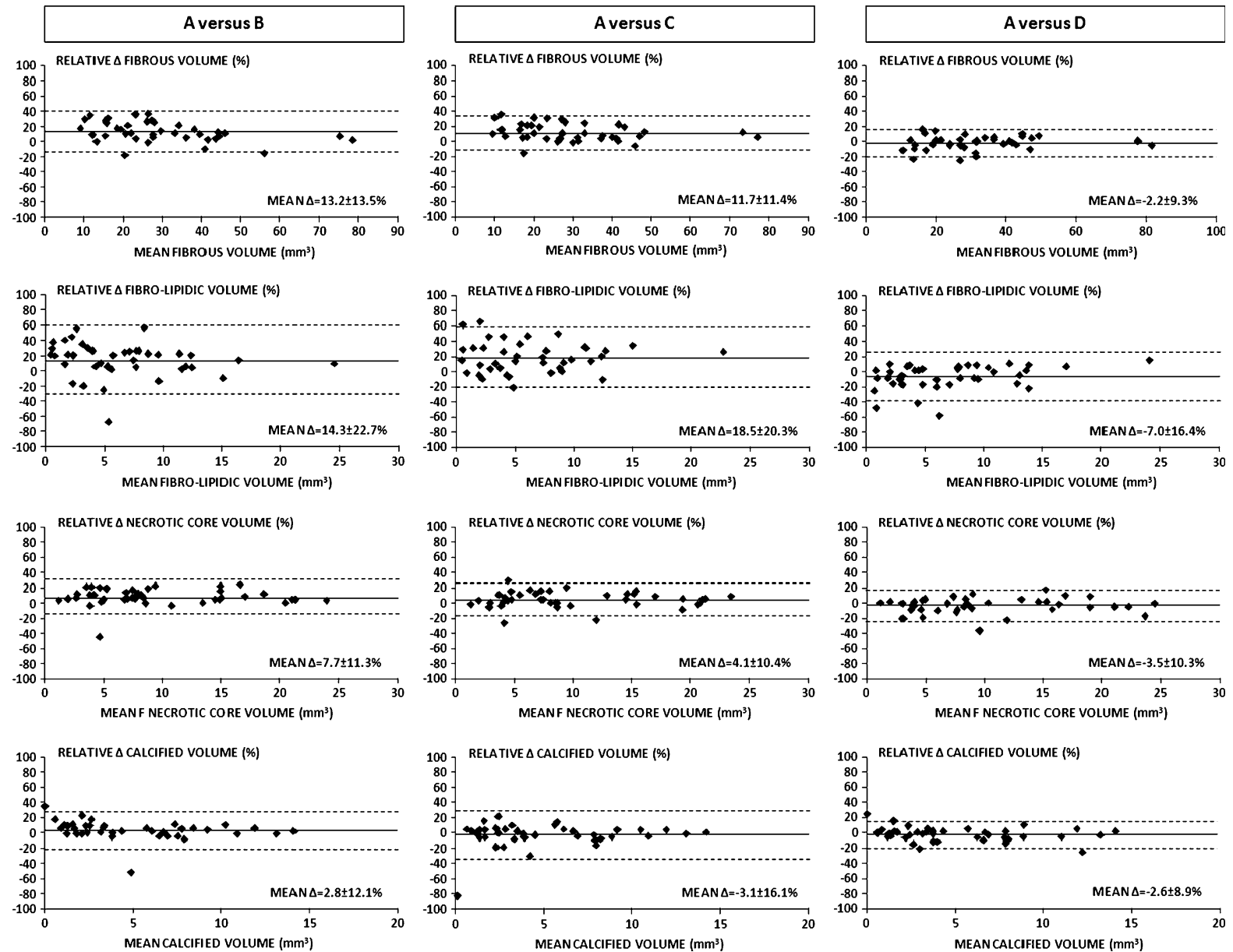

Fig. 4 a Agreement of repeated VH-IVUS measurements of compositional volumes. Agreement of repeated VH-IVUS measurements of plaque composition between center $A$ versus $B$ (left), center $A$ versus $C$ (mid) and center $A$ versus $D$ (right). $\Delta=$ difference. b Agreement of repeated VH-IVUS measurements of

the lumen and/or vessel borders, differences in the interpolation of the vessel contour at the site of sidebranches or behind calcified areas, and misinterpretation of thrombus and soft plaque adjacent to the lumen, which could theoretically have introduced larger measurement variability. The nature of such advanced lesions prior to PCI with more calcification, complex lesions and the IVUS probe against vessel wall/plaque, may result in increased difficulties of border detection in contrast with mild-to-moderate diseased coronary segments. It is likely that small differences or failures in contour detection will translate into (larger) errors of measurements of plaque composition. Therefore, our present study underlines the necessity to analyze compositional volumes. Agreement of repeated VH-IVUS measurements of plaque composition between center $B$ versus $C$ (left), center $B$ versus $D$ (mid) and center $C$ versus $D$ (right). $\Delta=$ difference

the VH-IVUS data of advanced coronary lesions prior to PCI at a single site or by an experienced core-lab to avoid measurement errors and misinterpretation of acquired data.

Recently, Shin et al. described a simplified contour detection method for the assessment of plaque composition with on VH-IVUS [27]. In Shin's method the lumen contour is drawn around the IVUS catheter, that is, without following the leading edge of the interface lumen intima. With this method only calcium and necrotic core can be assessed and related to total vessel area [27]. Shin et al. were able to demonstrate that coronary lesions with a greater amount of dense calcium volume and percent necrotic core to external 

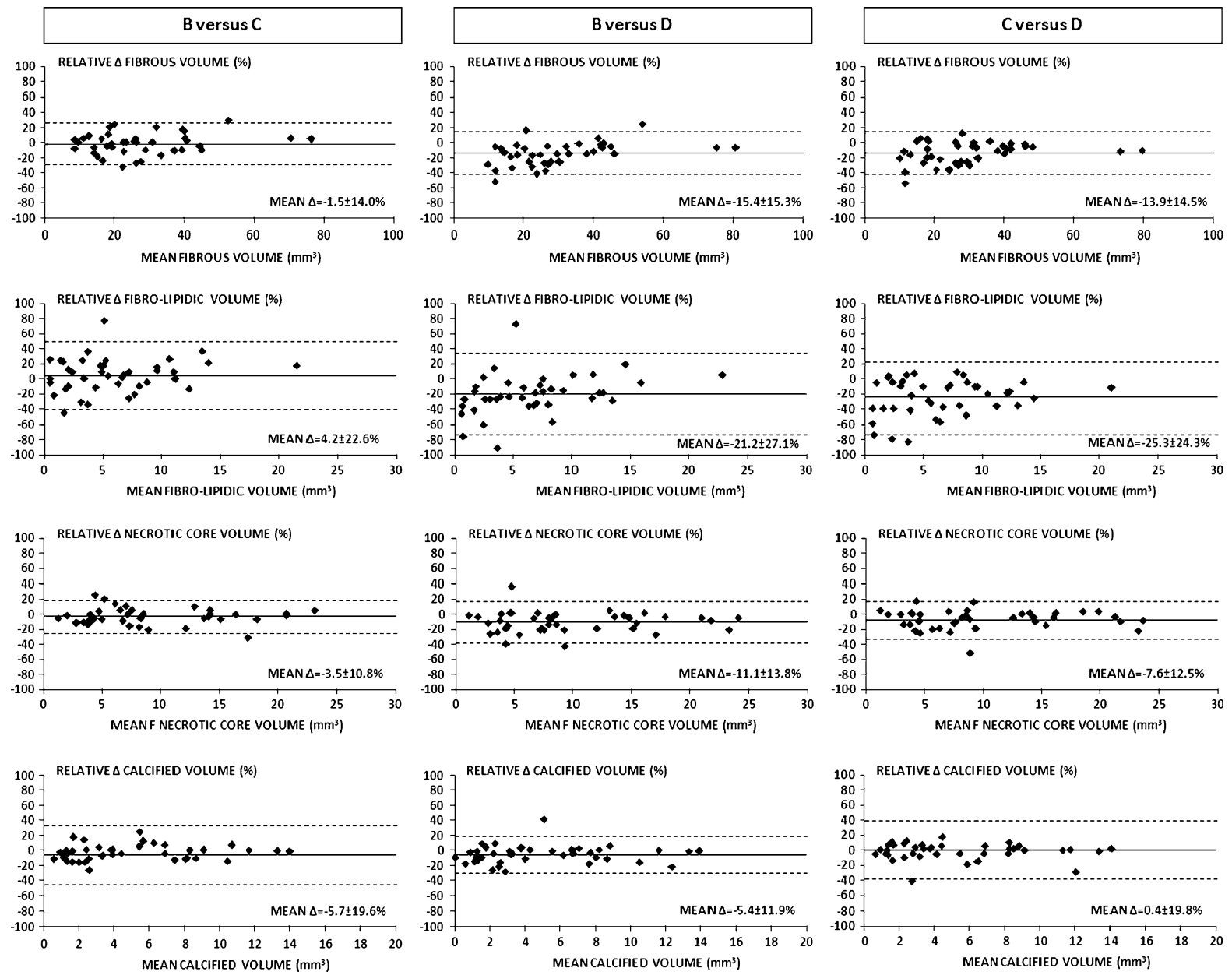

Fig. 4 continued

elastic membrane show more post-PCI myocardial injury [28]. Nevertheless, exclusive application of this method is limited by incompleteness of the geometrical and compositional data (e.g., no data on lumen and plaque size, and no information on fibrous or fibro-lipidic tissue).

\section{Limitations}

The present study was performed in an offline setting in coronary segments with advanced coronary atherosclerosis prior to PCI; therefore, our findings cannot be extrapolated to VH-IVUS reproducibility studies in an online setting in the catheterization laboratory or following stent implantation. Similar to other studies with IVUS and VH-IVUS, we excluded very tortuous and severely calcified vessels that could have led to non-uniform pullbacks and/or inability to detect the (external) vessel contour [9, 21, 23]. We used the pcVH software (available in all four centers) to perform IVUS image analyses in entire coronary segments. Meanwhile a newer computer software is available, however, this does not affect the importance of the present study. The purpose of out present study was to examine systematic between-center differences when analyzing lumen and vessel contours with a semi-automated IVUS analysis program in this specific set of coronary lesions; it was not our aim to test a specific software release. In addition, the betweencenter differences of the present study were mainly explained by differences in manual contour editing, which is still generally not abandoned by the most recent IVUS analysis software. The variability between different IVUS catheters or pullback devices, 
repeated pullbacks, and independent selections of the segment of interest were not addressed in our present multicenter study, as this study focused on the assessment of measurement reproducibility in predefined coronary segments that contained target lesions prior to PCI.

\section{Conclusions}

A central analysis for VH-IVUS multicenter studies of lesions prior to PCI should be pursued. Moreover, it may be problematical to pool VH-IVUS data of individual trials that are analyzed by independent IVUS centers.

Conflict of interest Dr. G.S. Mintz is a consultant to Volcano Corp. No other relevant conflict of interest was disclosed. This investigator-initiated study was not funded.

Open Access This article is distributed under the terms of the Creative Commons Attribution Noncommercial License which permits any noncommercial use, distribution, and reproduction in any medium, provided the original author(s) and source are credited.

\section{References}

1. Garcia-Garcia HM, Mintz GS, Lerman A, Vince DG, Margolis MP, van Es GA, Morel MA, Nair A, Virmani R, Burke AP, Stone GW, Serruys PW (2009) Tissue characterisation using intravascular radiofrequency data analysis: recommendations for acquisition, analysis, interpretation and reporting. Eurointervention 5(2):177-189

2. Hartmann M, Mattern ES, Huisman J, van Houwelingen GK, de Man FH, Stoel MG, Danse PW, Louwerenburg HW, von Birgelen C (2009) Reproducibility of volumetric intravascular ultrasound radiofrequency-based analysis of coronary plaque composition in vivo. Int $\mathrm{J}$ Cardiovasc Imaging 25(1):13-23

3. König A, Margolis MP, Virmani R, Holmes D, Klauss V (2008) Technology insight: in vivo coronary plaque classification by intravascular ultrasonography radiofrequency analysis. Nat Clin Pract Cardiovasc Med 5(4):219-229

4. König A, Klauss V (2007) Virtual histology. Heart 93(8): 977-982

5. Mintz GS, Nissen SE, Anderson WD, Bailey SR, Erbel R, Fitzgerald PJ, Pinto FJ, Rosenfield K, Siegel RJ, Tuzcu EM, Yock PG (2001) American college of cardiology clinical expert consensus document on standards for acquisition, measurement and reporting of intravascular ultrasound studies (IVUS). A report of the american college of cardiology task force on clinical expert consensus documents. J Am Coll Cardiol 37(5):1478-1492
6. Nair A, Kuban BD, Tuzcu EM, Schoenhagen P, Nissen SE, Vince DG (2002) Coronary plaque classification with intravascular ultrasound radiofrequency data analysis. Circulation 106(17):2200-2206

7. Nasu K, Tsuchikane E, Katoh O, Vince DG, Virmani R, Surmely JF, Murata A, Takeda Y, Ito T, Ehara M, Matsubara T, Terashima M, Suzuki T (2006) Accuracy of in vivo coronary plaque morphology assessment: a validation study of in vivo virtual histology compared with in vitro histopathology. J Am Coll Cardiol 47(12):2405-2412

8. Prasad A, Cipher DJ, Prasad A, Mohandas A, Roesle M, Brilakis ES, Banerjee S (2008) Reproducibility of intravascular ultrasound virtual histology analysis. Cardiovasc Revasc Med 9(2):71-77

9. Rodriguez-Granillo GA, Vaina S, Garcia-Garcia HM, Valgimigli M, Duckers E, van Geuns RJ, Regar E, van der Giessen WJ, Bressers M, Goedhart D, Morel MA, de Feyter PJ, Serruys PW (2006) Reproducibility of intravascular ultrasound radiofrequency data analysis: implications for the design of longitudinal studies. Int J Cardiovasc Imaging 22(5):621-631

10. Van Herck J, De Meyer G, Ennekens G, Van Herck P, Herman A, Vrints C (2009) Validation of in vivo plaque characterisation by virtual histology in a rabbit model of atherosclerosis. EuroIntervention 5(1):149-156

11. Böse D, von Birgelen C, Zhou XY, Schmermund A, Philipp S, Sack S, Konorza T, Mohlenkamp S, Leineweber K, Kleinbongard P, Wijns W, Heusch G, Erbel R (2008) Impact of atherosclerotic plaque composition on coronary microembolization during percutaneous coronary interventions. Basic Res Cardiol 103(6):587-597

12. Garcia-Garcia HM, Shen Z, Piazza N (2009) Study of restenosis in drug eluting stents: new insights from greyscale intravascular ultrasound and virtual histology. EuroIntervention 5(Suppl D):D84-D92

13. Garcia-Garcia HM, Gonzalo N, Kukreja N, Alfonso F (2008) Greyscale intravascular ultrasound and IVUSradiofrequency tissue characterisation to improve understanding of the mechanisms of coronary stent thrombosis in drug-eluting stents. EuroIntervention 4(Suppl C):C33-C38

14. Hong YJ, Jeong MH, Choi YH, Ko JS, Lee MG, Kang WY, Lee SE, Kim SH, Park KH, Sim DS, Yoon NS, Youn HJ, Kim KH, Park HW, Kim JH, Ahn Y, Cho JG, Park JC, Kang JC (2011) Impact of plaque components on no-reflow phenomenon after stent deployment in patients with acute coronary syndrome: a virtual histology-intravascular ultrasound analysis. Eur Heart J 32(16):2059-2066

15. Hong YJ, Mintz GS, Kim SW, Lee SY, Okabe T, Pichard AD, Satler LF, Waksman R, Kent KM, Suddath WO, Weissman NJ (2009) Impact of plaque composition on cardiac troponin elevation after percutaneous coronary intervention: an ultrasound analysis. JACC Cardiovasc Imaging 2(4):458-468

16. Kawaguchi R, Oshima S, Jingu M, Tsurugaya H, Toyama T, Hoshizaki H, Taniguchi K (2007) Usefulness of virtual histology intravascular ultrasound to predict distal embolization for ST-segment elevation myocardial infarction. J Am Coll Cardiol 50(17):1641-1646

17. Kim SH, Hong MK, Park DW, Lee SW, Kim YH, Lee CW, Kim JJ, Park SW, Park SJ (2009) Impact of plaque 
characteristics analyzed by intravascular ultrasound on long-term clinical outcomes. Am J Cardiol 103(9):1221-1226

18. Nakamura T, Kubo N, Ako J, Momomura S (2007) Angiographic no-reflow phenomenon and plaque characteristics by virtual histology intravascular ultrasound in patients with acute myocardial infarction. J Interv Cardiol 20(5):335-339

19. Rodriguez-Granillo GA, Garcia-Garcia HM, Mc Fadden EP, Valgimigli M, Aoki J, de Feyter PJ, Serruys PW (2005) In vivo intravascular ultrasound-derived thin-cap fibroatheroma detection using ultrasound radiofrequency data analysis. J Am Coll Cardiol 46(11):2038-2042

20. Kawamoto T, Okura H, Koyama Y, Toda I, Taguchi H, Tamita K, Yamamuro A, Yoshimura Y, Neishi Y, Toyota E, Yoshida K (2007) The relationship between coronary plaque characteristics and small embolic particles during coronary stent implantation. J Am Coll Cardiol 50(17):1635-1640

21. Huisman J, Egede R, Rdzanek A, Böse D, Erbel R, Kochman J, Jensen LO, van der Palen J, Hartmann M, Mintz GS, von Birgelen C (2010) Between-centre reproducibility of volumetric intravascular ultrasound radiofrequency-based analyses in mild-to-moderate coronary atherosclerosis: an international multicentre study. Eurointervention 5:925-931

22. Bruining N, von Birgelen C, de Feyter PJ, Ligthart J, Li W, Serruys PW, Roelandt JR (1998) ECG-gated versus nongated three-dimensional intracoronary ultrasound analysis: implications for volumetric measurements. Cathet Cardiovasc Diagn 43(3):254-260
23. Huisman J, Hartmann M, Mattern ES, Mintz GS, Basalus MW, van Houwelingen GK, Verhorst PM, von Birgelen C (2010) Impact of analyzing less image frames per segment for radiofrequency-based volumetric intravascular ultrasound measurements in mild-to-moderate coronary atherosclerosis. Int J Cardiovasc Imaging 26(5):487-497

24. Bland JM, Altman DG (1986) Statistical methods for assessing agreement between two methods of clinical measurement. Lancet 1(8476):307-310

25. Huisman J, Hartmann M, von Birgelen C (2011) Ultrasound and light: friend or foe? On the role of intravascular ultrasound in the era of optical coherence tomography. Int $\mathbf{J}$ Cardiovasc Imaging 27(2):209-214

26. von Birgelen C, Huisman J, Hartmann M (2010) Is size really all that matters? Remarks on size and necrotic core content of atherosclerotic plaques. Int J Cardiovasc Imaging 26(2):173-176

27. Shin ES, Garcia-Garcia HM, Serruys PW (2010) A new method to measure necrotic core and calcium content in coronary plaques using intravascular ultrasound radiofrequency-based analysis. Int J Cardiovasc Imaging 26(4): 387-396

28. Shin ES, Garcia-Garcia HM, Garg S, Park J, Kim SJ, Serruys PW (2011) The assessment of Shin's method for the prediction of creatinine kinase-MB elevation after percutaneous coronary intervention: an intravascular ultrasound study. Int J Cardiovasc Imaging 27(6):883-892 